\title{
Soccer boom may score for Japanese science
}

Tokyo. Will Japan's sudden enthusiasm for soccer, marked by the start last month of Japan's first professional soccer league, help to break through the rigid ceiling on government spending for science in the universities? The basis for that seemingly odd question is a history of using part of the proceeds

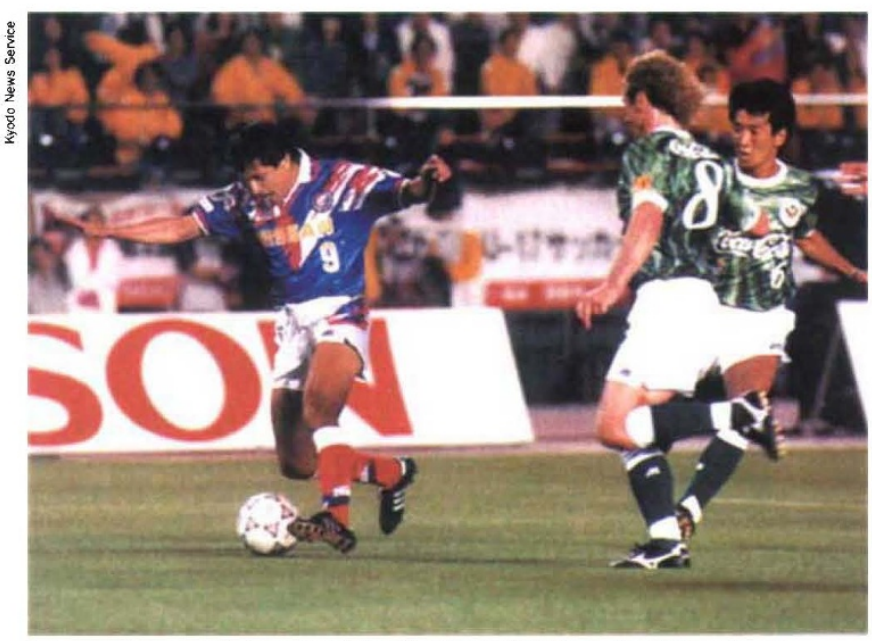

Japan gets a kick out of its first professional soccer league.

from gambling on sports to support science and technology.

The popularity of soccer has skyrocketed after the arrival of famous Western soccer stars, like Britain's Gary Lineker, to play on teams sponsored by companies and local governments. The creation of the new J-league has prompted members of Japan's ruling Liberal Democratic Party (LDP) to consider a football pool betting system, like that in Britain and Italy, to finance improvements to the social infrastructure.

At present, the LDP politicians promoting the scheme are suggesting only that profits be fed into the support of sports, in particular soccer. But past experience suggests that some of the money may be diverted into science and technology.

In 1957, the postwar popularity of bicycle races led local governments and the Ministry of International Trade and Industry (MITI) to establish the Japan Keirin Association, an organization that funnelled some of the huge profits from betting on bicycle races into the bicycle industry as well as into the sport itself. Over the years, the range of industries and activities supported by Keirin have expanded to the point where the money frequently supports government-industry research projects and international conferences in Japan in frontier areas of science and technology (see right).

Similarly, the Ministry of Agriculture, Forestry and Fisheries has used some of the profits from gambling on horse races, which are run by the Japan Racing Association, to support science. For example, the ministry's new rice genome project gets a large proportion of its funding from this source (see Nature 356, 181; 1992). The Ministry of Transport also feeds some of the profits from betting on motorboat races under its jurisdiction into the development of technology.

Keirin provides about $¥ 35$ billion (US\$315 million) a year or the equivalent of about 12 per cent of MITI's overall research and development budget. These extra sources of funds have given these ministries a way to fund projects that otherwise might have been impossible because of the squeeze on government expenditures from Japan's huge national government debt. But the Ministry of Education, Science and Culture (MESC) has no such source of funds, and the universities and the university research system under MESC have suffered greatly during the last decade of fiscal restraint. This is where soccer might help.

It is widely anticipated that the proposed football pools system will be overseen by MESC; the ministry is already responsible for high school soccer teams. Furthermore, Kosuke Hori, a former minister of education, science and culture, who has been seeking ways to break through the ceiling on MESC's budget, is leading an LDP team looking into ways of promoting sports, including the proposed soccer pools.

But the public is increasingly opposed to the idea, with parents worrying that children might be led astray by betting on football and the leading opposition party, the Social Democratic Party, officially opposed to the idea. To counter that sentiment, one politician from the New Sports Party returned from a visit to Italy expressing the view that filling in football pool forms requires thought and intelligence and could be educational for children.

Leading academics are also sceptical that universities are prepared to accept funds, no matter how indirect, from such a source. "It's easier for national institutes to accept such money", says the former president of one leading national university. But given the reluctance of the powerful Ministry of Finance to increase MESC's budget, soccer may offer an irresistible scoring opportunity for science.

David Swinbanks

\section{How bicycle races power science and technology}

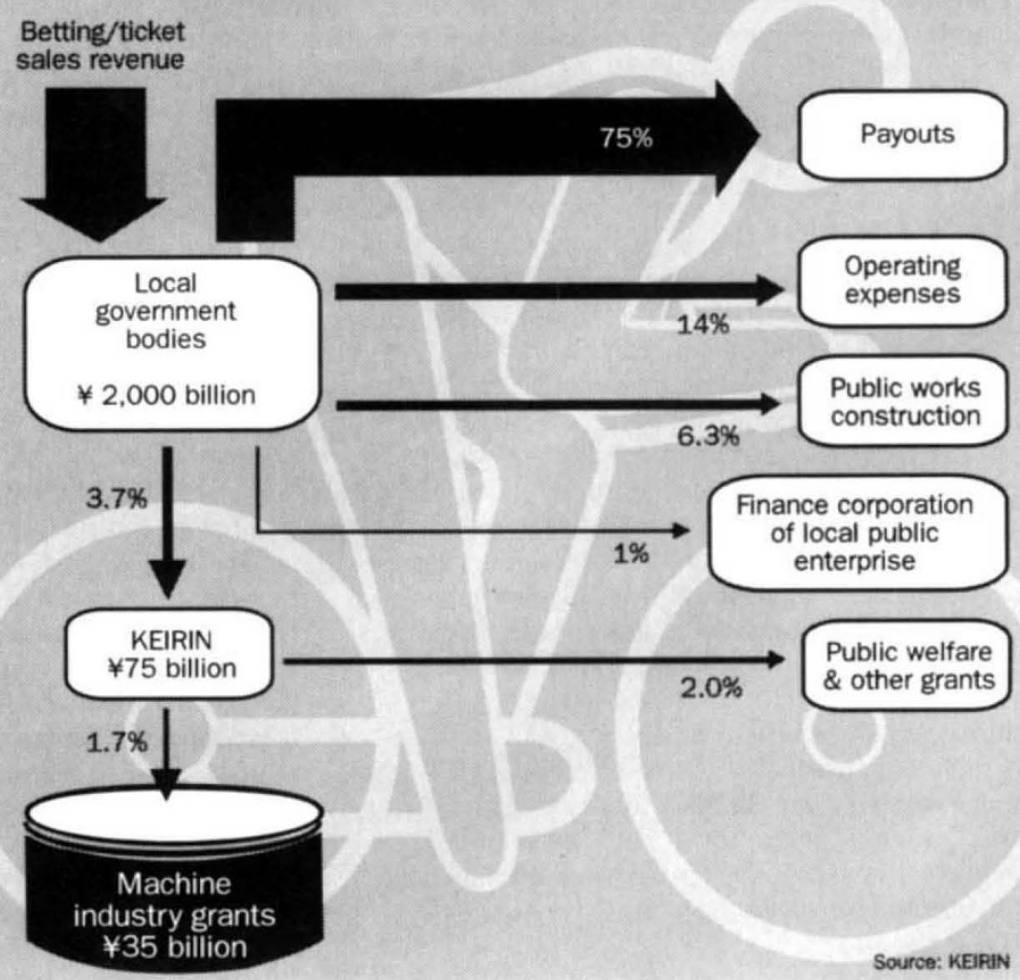

